\title{
CONTROL SOCIAL Y DIVERSIÓN PÚBLICA EN COSTA RICA (1880 -1930).
}

\author{
Francisco Enríquez Solano, \\ Escuela de Historia, Universidad de Costa Rica \\ fenrique@cariari.ucr.ac.cr
}

Este artículo fue expuesto en el XIX Congreso Internacional de Ciencias Históricas, Oslo, 6 13 agosto del 2000

El control social de las diversiones públicas en Costa Rica se empieza a sistematizar tras la llegada de los liberales al poder, a finales del siglo XIX. Sin embargo la Iglesia católica también pone en práctica una serie de restricciones dirigidas a controlar y a orientar la diversión.

A partir de los primeros códigos se observa cómo el control es ejercido por todo un aparato burocrático que tiende a orientar requerimientos y procesos para el funcionamiento de cada diversión pública. Así, surge el primer reglamento de Policía en 1849. No obstante con el tiempo, al afianzarse más el Estado y al ampliarse las diversiones, surgen reformas a dicho reglamento. También aparecen decretos y otros reglamentos que en forma específica se refieren a juegos, espectáculos públicos, licores, días feriados, cinematógrafos, peleas de gallos, etc. En todos aparecen las instituciones o personas que se encargan de velar por su cumplimiento, se contempla el papel que en primer instancia juega el gobernador, luego la municipalidad y el agente de policía o el jefe político de cada lugar.

Debido a que las leyes son generales y de acatamiento obligatorio, rigen para todo el país, a excepción de la salvedad que aparece en los reglamentos donde se hace distinción de ciudades y pueblos, o donde se dan disposiciones que cambian según el número de habitantes.

Las principales diversiones públicas que se miran en una comunidad rural son turnos, juegos, fiestas religiosas, o espectáculos públicos como teatro o cine, y bailes. Por lo tanto, se meditan también elementos que forman parte de una de estas actividades como las procesiones y las rifas, o sitios que sirven como centro principal de determinada diversión como las 
cantinas. Por ello el análisis del control social se hace a partir de las diversiones, bajo el supuesto de que ellas norman la vida de las comunidades rurales del Valle Central.

\section{La Reglamentación de la Diversión Pública.}

Desde 1849, el Reglamento de Policía que se emitió en esa época deslinda el campo entre las diversiones públicas y las privadas[1] Por consiguiente en su artículo 160 define a las diversiones públicas como:

“...aquellas adonde se concurre por entretenimiento o recreo, sin necesidad de convite, y son diversiones privadas aquellas en que, previa invitación, se reúnen determinadas personas con el mismo objeto. Corresponden a las primeras las funciones cívicas, representaciones teatrales, espectáculos, exhibiciones de juglares, maromas y otras semejantes promovidas por especulación de particulares y corresponden a las segundas los bailes, banquetes, paseos privados, serenatas y otras diversiones semejantes."

De lo anterior se desprende que diversión pública es aquella a la que asiste voluntariamente la gente. Para llevarla a cabo quienes organizan la actividad deben solicitar permiso a la policía, mencionando el lugar, los días y el precio de la entrada al evento. De lo contrario, se les obliga a pagar una multa, además, si lo que presentan ofende a la moral pública la policía les retirará el permiso.

En el Reglamento se observa que la diversión pública de la época se restringe a fiestas cívicas, representaciones teatrales, espectáculos, veladas, exhibiciones de juglares, maromas (circos), billares, juegos de cartas y peleas de gallos. Los únicos establecimientos donde se 
lleva a cabo la diversión pública son: los teatros, billares, galleras y taquillas. Lo dispuesto en ese reglamento se mantiene en su esencia y muchas de estas diversiones se regulan con mayor detalle en otras leyes y reglamentos, como la Ley de Juegos (1886 y 1917), la de Licores (1903 y1907), la de Espectáculos Públicos (1906), la del Cierre dominical (1903 y 1934)[2], las que al igual que otras surgen con mayor especificidad a partir de la consolidación del Estado liberal.

En 1908, durante la administración de Cleto González Víquez se vuelve a emitir otro Reglamento de Policía y en el mismo se introducen algunos artículos con prácticas culturales por realizarse en la época. En él se nota que las serenatas causan algún tipo de inconveniente en las localidades. Asimismo los bailes se ejecutan con mayor frecuencia y ya salen del ámbito privado, por ello, a pesar de que no se indica que se debe solicitar permiso para legalizarlos, se ordena a la policía para que "este a la expectativa y vigile el orden desde la calle, tanto para disponer del buen arreglo de la entrada de concurrentes, como para que estos no cometan ninguna incorrección".[3]

Debido al incremento de turnos y ferias en las localidades, el reglamento señala que estas se impedirán si no cuentan con el permiso respectivo. A la vez se indica que se cumplirá estrictamente con el Reglamento de Espectáculos Públicos aprobado en 1906. Sobre todo se insiste que las funciones no deben terminar después de la medianoche y que las personas mantendrán el orden y el respeto.

De este reglamento, la parte que más refleja la situación que se da en las comunidades rurales es la normativa del artículo 173 que se refiere a las fiestas cívicas. En él se dice que no se permiten "gritos descompuestos", o la circulación de coches o caballos donde se concentra el público, que en las retretas o recreos, la gente circule de tal manera "que no se estorben unos a otros". Así mismo, en las mascaradas se velará porque los disfrazados no irrespeten a los espectadores. Con estas disposiciones se pretende regular y ordenar diversiones donde ya existen ciertas costumbres.

La llegada del fonógrafo y la costumbre de tocar instrumentos musicales en las casas de habitación, sobre todo a raíz del incremento de las filarmonías locales a principios de siglo, obliga a introducir reformas como la que dispone que "la policía no permitirá que se atormente 
a los vecinos con el abuso de fonógrafos, flautas, cornetines, tambores o cualquier otro aparato o instrumento de esa índole".[4]

Por su parte la Iglesia también presenta una normativa para divertirse que se asocia a frecuentes llamados a la moralidad. Por ejemplo el Mensajero del Clerode enero de 1920 considera que el cura no debe quedarse aislado sino que debe promover la diversión popular: "Uno, pues, de los mejores beneficios que puede hacer el cura a su parroquia y a su pueblo, es procurarles alegría y como la alegría se fomenta y sostiene con las fiestas y diversiones, unas de las más buenas acciones del cura había de ser el fomentar estas diversiones y fiestas".[5]

Lo anterior parte del criterio de que los excesos en las diversiones son frecuentes y que es más fácil prevenirlos fomentando "diversiones buenas", pero ¿qué es diversión para la Iglesia? Según El Mensajero del Clero “diversión, recreación, distracción, juegos, pasatiempos, fiestas, todas estas palabras parecen parientes y aún algunas sinónimos"[6]. El pueblo necesita diversión y la Iglesia siente la obligación de proporcionársela, o cómo lo dice el mencionado periódico "diversiones en la Iglesia y diversiones fuera de la Iglesia". Las diversiones dentro de la Iglesia son las propias del ritual de la misa o función. En este sentido, la catequesis, la primera comunión, las bendiciones, las flores de mayo, los santos patronos o las misas deben ser parte de esta diversión o fiesta religiosa. Sin embargo, la Iglesia está consciente que la mayor diversión dentro de la Iglesia lo constituyen las procesiones de los santos patronos, las de Corpus, Cristo Rey y Semana Santa, porque en ella participan muchas personas “...el sacerdote debe de procurar que salgan muy agradables y espléndidas las fiestas del Señor. Sobre todo las procesiones que se prestan a mucha alegría y que suelen entretener días semanas enteras a veces a muchísima gente.”[7]

\section{TURNOS Y RIFAS.}

Los turnos tienen la regulación de la ley del 30 de julio de 1884 que obliga a las juntas a solicitar el debido permiso al Poder Ejecutivo y este tiene la potestad de determinar el número 
de turnos que se efectúan al año en cada localidad. Sin embargo, el control sobre los mismo se extiende aun más cuando se emite una disposición en 1890 que obliga a que una tercera parte de las ganancias obtenidas se destinen a la construcción de edificios escolares de cada comunidad. La misma, provoca el disgusto en los sacerdotes y por ello consultan en forma constante al Obispo para saber si deben cumplir con la misma.[8] En casos extremos se llega a situaciones como la planteada en la Villa de Guadalupe, San José lugar donde el cura se enfrenta a la comunidad y se opone a destinar los recursos para el edificio escolar.

En 1904, los diputados Vidal Quirós y Julio Acosta proponen un proyecto de ley que tiende a normar en forma definitiva la distribución de fondos que se obtiene en las comunidades a través de los turnos que llevan a cabo las distintas parroquias. Los legisladores proponen "reglamentar las fiestas, representaciones, ferias y turnos que se organicen para allegar fondos a favor de las iglesias, de los hospitales o de la Educación Común y a dividir el producto neto que se obtenga por iguales partes entre las tres instituciones de que se ha hecho referencia".[9]

Para ello el mencionado proyecto propone que cada una de estas actividades sean dirigidas y presididas por el cura, el presidente de la junta de educación y el representante de la respectiva junta de caridad del lugar donde se verifica la actividad.

El proyecto tiene como fin visible el evitar que a la gente se le pida en forma constante fondos para diversas actividades. Sin embargo, el hecho es que como se demostró con anterioridad, el turno constituye el evento más generalizado de todos los mencionados, pues es la diversión pública con más arraigo y en su mayoría es una actividad propiciada por la Iglesia católica para allegarse fondos. Por lo que un proyecto de esta naturaleza claramente se dirige a las arcas de esta institución. Por ello se da la reacción de los sacerdotes que, como el del Cantón Alajuela de Palmares, envía el siguiente telegrama a los congresistas el 2 de agosto de 1904, "los turnos se verifican con los donativos generalmente ofrecidos por los fieles para la edificación o reparación de los templos católicos. Esta es la intención de los donantes sobre cuya voluntad no puede legislarse siempre y sus cuotas o contribuciones no se festinan." [10] 
En ese mismo sentido el 30 de julio de 1904 llega al Congreso un alegato firmado por 30 sacerdotes de todas las parroquias, incluida la firma del Obispo, en el cual se alega que el proyecto tiene una serie de inconvenientes lesivos a la Iglesia, pues por un lado los curas por prohibición canónica no pueden asistir a los bailes, representaciones teatrales u otras fiestas. Por otro lado consideran que las juntas edificadoras y los hospitales tienen rentas propias, en cambio las iglesias no tienen esos recursos. Como prueba que con las rentas fijas las instituciones mencionadas cubren sus necesidades mencionan que:

"estas instituciones pocas veces verifican y verificarán turnos, ferias, representaciones y bailes para colectar fondos y por consiguiente muy pocas veces se vería el caso de que de éstos participaren las iglesias... al contrario, cada lugar, cada distrito desea construir, refaccionar u ornamentar su templo, y los turnos es innegable que se verifican con frecuencia, ya sea en un lugar, ya sea en otro, e la República.”[11]

Los sacerdotes alegan finalmente que en el proyecto de ley hay falta de equidad y que se percibe en el mismo una gran hostilidad al culto católico, y que ello está "hábilmente disfrazado con ropaje de caridad y pedagogía", por lo que piden que el mismo no se apruebe. La presión de la Iglesia surte efecto y el proyecto ni siquiera se somete a votación.[12]

En julio de 1917 el diputado Gil Mayorga, vuelve a presentar un proyecto de ley casi en los mismos términos que el que se presentó en 1904. Sin embargo, de nuevo se rechaza esta vez debido al dictamen negativo que realizan las comisiones legislativas de Beneficencia e Instrucción Pública. En el mismo alegan que aparte de que se coarta la libertad de que los individuos dispongan de sus bienes como crean más conveniente, la forma en que intervendrían las instituciones para distribuir sus bienes pueden causar problemas en las localidades.[13]

Debido a que realizar rifas en cada evento es una práctica extendida, esta práctica también es objeto de regulación. Así según la ley del 30 de julio de 1884, para efectuar una rifa se debe solicitar permiso al Secretario de Gobernación. Una vez autorizada, el jefe político local debe de velar porque a los artículos que se rifen no se les cargue más de un veinticinco por ciento sobre el valor real, para constatar dicha situación la autoridad política local debe nombrar dos peritos.[14] 
En San Vicente de Moravia, San José la práctica de hacer rifas es una costumbre muy generalizada y a veces ocasiona problemas en la comunidad. Por ello la municipalidad en 1920 toma el siguiente acuerdo[15] "llamar la atención al jefe político para que realice un control más eficaz sobre las rifas, pues algunas se están realizando sin los permisos y otras no cumplen con lo prometido".

\section{BAILES PUBLICOS:}

El baile como diversión pública se viene a controlar en la década de 1930 con las regulaciones que surgieron en esa década. El instrumento que sirvió para tal fin fue un reglamento emitido el 17 de diciembre de 1930.[16] En el mismo se establece el mecanismo burocrático por medio del cual se puede realizar un baile. Así, el gobernador es la única persona que puede autorizar un baile, una vez que lo resuelve lo comunica a la respectiva agencia de policía para que ésta proceda a determinar la vigilancia del mismo.

En el caso de apertura de salones, sólo se puede hacer sí el local tiene condiciones de seguridad e higiene y cuando el empresario cancela el impuesto correspondiente. Previo a ello la Dirección de Policía debe de rendir un informe donde mencione las calidades morales de la persona que manejará el negocio, la clase de vecindario donde se va a establecer y si el vecindario está de acuerdo con dicha instalación, o si se dificulta el ingreso para la vigilancia policial.

Los salones no se pueden establecer en la vecindad de templos y escuelas, no pueden comunicarse con otras partes internas del edificio, ni con billares, cantinas o casas vecinas. No se pueden abrir antes de las 7 p.m. y deben cerrarse a más tardar a las 12 p.m. Además, es prohibido vender licores dentro de los salones y por ello tampoco se pueden dar patentes para cantinas internas. Dispone también dicho reglamento que en los salones debe de haber orden y respeto, para ello se prohibe la permanencia de personas ebrias y de menores de 18 años. 
Debido a lo riguroso de las disposiciones para abrir salones de baile, no se abren frecuentemente, por lo que se aprovechan las sedes de los clubes deportivos para realizar los bailes. Pero una práctica muy frecuente es realizar los bailes en las escuelas. Así, se desprende de un artículo que aparece en la Revista Costarricenseen 1933, bajo el título "la secretaría de Educación Pública no permite los bailes en la Escuela" y que entre otras cosas menciona que "en el campo con marcada frecuencia se baila y como el lugar más apropiado para ello es la Escuela, allí se reúnen para el dancing, toda clase de personas.”[17]

La Iglesia católica lanza una campaña muy fuerte contra el baile, al cual define en febrero de 1927 como:

“...una reunión, una mezcla de personas de ambos sexos, por lo regular jóvenes y apasionados, ardientes, dotados de gran viveza de carácter, y engalanados con los atavíos más seductores, y que sobreexcitados por el resplandor de las bujías, los acordes de la música, las evoluciones del cuerpo, y a veces por las bebidas, asidos de la mano o de la cintura dan vuelta en un espacio más o menos reducido.”[18]

Según las prédicas de la Iglesia, aunque el baile tiene una tradición religiosa, esta se ha distorsionado y por más que el padre de familia acompañe a sus hijos a los mismos, estos pueden caer en los peligros que traen estos eventos. Debido a la generalización de los bailes públicos, la Iglesia se lanza contra los mismos al aducir que:

"los bailes públicos son en las aldeas y las ciudades los medios más activos de la corrupción de costumbres, porque la vigilancia de las familias es allí casi nula, y algunas veces imposibles. Al volver de los bailes públicos se completa el mal que había comenzado en ellos. El baile público es la ruina de las costumbres del pueblo.’[19]

A la vez que denuncia que estos bailes públicos corrompen las costumbres porque hacen que las jóvenes "entren en pecado", la Iglesia se manifiesta impotente para detener la costumbre que cada vez se generaliza más de efectuar bailes las tardes de los domingos. Por ello con gran pesadumbre los voceros de la misma afirman en 1927 que: 
"es un desconsuelo para los pobres curas que ven el lobo arrebatar, una tras otra, sus ovejas, sin poder defenderlas, porque no quieren ser defendidas. Por más que prediquen contra el baile y hagan todas las amonestaciones posibles, la voz de los sentidos y del placer es más escuchada que la suya; y si desesperando del resultado, tratan de impedir el baile público, concitan contra sí a toda la juventud que tiene afición al baile, y a los vendedores de vino y de comestibles que desean ganar. Así todos se conjuran contra ellos y cada domingo y día festivo experimentan el dolor de ver el demonio de la sensualidad, destruir a la tarde por el escándalo y el mal ejemplo, el poco bien que su palabra pudo producir a la mañana.”[20]

Los argumentos que se esgrimen contra el baile son de todo tipo pues aparte de criterios de orden moral y religioso se hace alusión a elementos de higiene y salud. El mensaje se dirige contra la sensualidad del mismo, la manera en que la mujer se viste y presenta en estas diversiones y el lenguaje que en ellas se propicia. El mensaje sobre todo se dirige a las mujeres haciéndoles un llamado para que no asistan a los mismos y así conserven su pureza, pues el solo asistir a un baile se considera pecado. Por tal razón, se hacen llamados a la juventud invocando el castigo y el temor, como este de 1927: “¿Qué joven quisiera ir al otro mundo inmediatamente después del baile, sin confesarse, aunque no tuviera en su conciencia más que la falta de haber asistido al baile?".[21]

\section{EL LICOR Y EL CONTROL DE LA SOCIABILIDAD EN LAS CANTINAS.}

En las poblaciones pequeñas, antes de la aparición de la municipalidad, se permite la venta de licor solo en el momento que se nombra a un agente de policía. Los primeros negocios que se abren se ubican cerca de la plaza, pues el Código Fiscal no permite que se establezca ningún puesto de venta de licor fuera de un radio de 84 metros a partir de la plaza,[22] esto porque así se puede llevar un mayor control sobre el mismo. Este código, establece que las municipalidades deben determinar el número de establecimientos de licor que se deben de permitir en una población, pero regula su número en forma proporcional a sus habitantes. Se dispone así: "en las cabeceras de cantones menores y en las poblaciones que sin ser cabeceras de cantón contaren con más de mil habitantes, de un establecimiento de licores extranjeros por cada quinientos habitantes, y de uno de licores del país por cada trescientos".[23] 
Junto con la restricción a la venta de licores se controla la sociabilidad que se genera en las cantinas y las diversiones públicas. Por ello, no se permite que en las cantinas se lleven a cabo juegos, aunque si se permite que funcionen billares en alguna pieza contigua. Lo anterior obedece a que la mesa de billar es muy cara y usualmente el dueño de la cantina es el dueño del billar. Además primero se establecen billares y después las cantinas. Esto queda evidente cuando el Código Fiscal establece que no se admite en los establecimientos de venta de licor ningún tipo de juego, ni aún los permitidos por la ley, pero se hace la excepción de que en cantones menores, previo permiso de la autoridad superior de policía, puede funcionar el billar contiguo a la cantina.[24]

También es frecuente la existencia de establecimientos que venden a la misma vez mercaderías y licores, para ello estos locales debía contar con patente para ambas actividades. Este tipo de negocio es el más frecuente y según lo mencionado con anterioridad en el cantón de Moravia habían 4 locales, de este tipo. Según don Marcos Huertas, "en San Vicente casi no habían problemas de alcoholismo, eso se debe a las buenas costumbres de la gente y también a la práctica de los agentes de policía de pasar en forma frecuente a vigilar las cantinas y llamar la atención al que se pasaba de tragos" [25]

Se da el caso de que en las pulperías que no tienen patente para vender licor, venden algún tipo de bebida fermentada (guarapo, chicha), pero ello se prohibe con la Ley de Licores de 1907[26]. En los establecimientos de venta exclusiva de licor no se permite la entrada de menores de edad, pero en la pulpería y cantina, se exige que una vez que el menor tenga su mercancía se retire. Para controlar el alcoholismo se prohibe también vender licor a las personas ebrias, y se dispone que, si se encuentra alguna en estado de ebriedad, se le sancione con una fuerte multa. Sin embargo, debido a que dicho problema social ya está muy entronizada en la sociedad se acuerda que los domingos y días feriados las boticas no pueden vender alcohol puro.[27]

La medida más directa contra las cantinas como sitios de sociabilidad es la que establece el artículo 30 de la Ley de Licores de 1907, el cual establece que "queda prohibida la permanencia de personas en los establecimientos en donde se expenden licores del país, por más tiempo que el necesario para la compra que hubieren entrado a hacer, o para consumir sin 
demora los licores comprados."[28] Aunque la infracción a este artículo se castiga con una fuerte multa, es difícil imaginar a un cantinero apurar a sus clientes para que beban rápido y se vayan del lugar.

Otra regulación que tiende al control de las cantinas como centros de sociabilidad es la del cierre dominical. Esta medida consiste en que para acatar el precepto religioso del descanso dominical todo establecimiento comercial debe cerrar al público el día domingo. Esta medida afecta no solo a las cantinas sino también a pulperías, almacenes, boticas y comercio en general. Así, según la Ley de Licores de 1903 las pulperías, tiendas, almacenes y cantinas deben cerrar a las 2 de la tarde los domingos y los días feriados. Sin embargo, en 1907 se promulga una nueva ley que es más estricta pues establece que las cantinas deben permanecer abiertas hasta las 12 del día y dispone que año con año este horario se reducirá hasta que a partir de 1910 no abrirán del todo.[29]

Sin embargo los dueños de establecimientos buscan la manera de obviar esta disposición y venden licores en las casas de habitación, por lo que el Secretario de Gobernación debe emitir una disposición para que se regule a las pulperías, billares y casas contiguas pues "frecuentemente se cometen abusos para burlar la ley en estos puntos, ya depositando cantidades en otros departamentos que no son usuales para el expendio, ya distribuyendo envases en las estanterías destinadas a artículos que no son exclusivamente de cantina.’[30]

Aparte de dicho mecanismo, los comerciantes aprovechan cualquier portillo de la ley y así siempre hacen peticiones para poder vender su producto. Así, en 1910, dos días feriados coinciden con el día domingo (15 de setiembre y 24 de diciembre), por lo que la Secretaría de Gobernación, ante una consulta hecha, se ve obligada a aclarar que por ser esos días feriados, no procede el alcance de los domingos, por lo que se acepta que los establecimientos de licores permanezcan abiertos hasta las 12 del día.[31]

Durante todo el período en estudio se observa, por un lado, la posición de los comerciantes que buscan ampliar el horario el domingo y los días feriados, por otra parte la posición del Estado que, en forma ambigua algunas veces, cede y flexibiliza la regulación. Con la ley de 1915 las pulperías pueden abrir hasta las 12 del día los domingos y días feriados. En 
cambio la ley de 1924 no permite abrir las cantinas los domingos, aún cuando sea feriado.[32] La Iglesia Católica, por su parte lanza también una dura prédica contra los que buscan eliminar o disminuir el cierre dominical. Por ello el Obispo Juan Gaspar Stork emite el 19 de marzo de 1912 una carta pastoral titulada. "La santificación del domingo y días festivos" en la que entre otras cosas se pronuncia contra cualquier modificación en lo que ha sido la tradición religiosa.

\begin{abstract}
"Por esto se comprende el por qué del procedimiento empleado por los enemigos de la Religión. Saben que el medio más seguro de lograr la destrucción del sentimiento religioso es la abolición de la santificación del domingo y la supresión de los días festivos; por lo mismo, si no pueden alcanzarla mediante una legislación intempestiva, procuran con mil diabólicos artificios separar a los incautos de los oficios de la Iglesia."[33]
\end{abstract}

De la cita anterior se desprende que se está ante un proceso de transición de un ocio todavía dominado por la religión a un ocio dominado por lo profano. También la Iglesia se pronuncia contra el consumo de licor, y llama la atención sobre el aumento de bebedores, por lo cual todos los días se observan hombres frecuentando cantinas. Su mensaje es que ello es malo, pues aparte de que el ambiente de estos lugares no es propicio, el licor produce un daño a la salud y fomenta la vagancia y la inmovilidad, tal y como aparece en un artículo del Eco Católico en julio de 1900:

"uno de los vicios más detestables que produce ociosidad, es la embriaguez. Este vicio repugnante, es la gangrena de la sociedad, el semillero de nefastos crímenes, la inagotable fuente de discordias y maldades, la lepra que corrompe a la juventud y la rémora del progreso. Quizás no haya otro vicio que se oponga más al progreso y bienestar de los pueblos...”[34]

Ante dicha situación, en los turnos que organiza la Iglesia no se lleva a cabo ninguna venta de licor, pero en forma general se observa la práctica de vender licor en locales o casas de 
particulares cerca de donde se llevan a cabo dichos eventos. Ello queda de manifiesto en una petición para hacer turnos dirigida al Secretario de Gobernación por la Junta Edificadora de la Iglesia de la Soledad en 1924, que dice, entre otras cosas, lo siguiente:

"tanto la Junta como la Comisión de Turnos nunca han querido ni quieren ventas de licores en días u horas prohibidos, pero como por experiencia se conoce que algunos vecinos o particulares venden, suplicamos a Ud. se sirva advertirlo a quien corresponda, pues deseamos que la policía cumpla de verdad".[35]

\section{TEATRO Y CINE.}

Los espectáculos públicos de las villas y ciudades estaban regulados por las mismas disposiciones que regulaba el Reglamento de Teatros y Espectáculos Públicos de la ciudad de San José, aprobado por la municipalidad Josefina en la sesión del 13 de diciembre de 1905. En este documento se regula la forma cómo deben de construirse los locales de los teatros, así como el trámite que se debe seguir para que se lleven a cabo los espectáculos públicos.

Para abrir un local de teatro deben de cumplirse las condiciones que aparecen en el mencionado reglamento. Así, se requiere que la municipalidad apruebe los planos del mismo. Los espectáculos públicos deben terminar a las doce de la noche a más tardar, tampoco se permite hacer ruido o hablar.[36] También regula el comportamiento que deben de seguir los espectadores "los cuales deben de guardar orden y compostura. En las representaciones en que sea preciso guardar silencio, no es lícito hablar, ni hacer ruido de ninguna especie".[37]

Tampoco se permite fumar, escupir o demostraciones que alteren el orden y sean "contrarias al decoro". Esta situación tiende a normar y a ordenar a un público no acostumbrado a compartir un recinto cerrado. En 1926 la Municipalidad de Moravia toma el acuerdo de permitir la construcción de un edificio para el teatro. Pero advierte que este se debe regir por los reglamentos vigentes para mantener la moral y buenas costumbres del lugar.[38] También en las actas municipales de Moravia encontramos una queja de los 
munícipes sobre el comportamiento de los vecinos en el cine. Así en setiembre de 1920 aparece lo siguiente.[39]

"se excita al Jefe Político para que por los medios que este a su alcance impida, corrija, y aún pene a los elementos que promuevan escándalos, empleen expresiones indecentes, rechiflas, pateos y golpes. Lo anterior con respecto a los escándalos de niños y adultos los domingos en las exhibiciones de cine en la casa de la escuela pública".

Sin embargo, aparentemente o el jefe político no cumplió con lo que se le indicó o el público no atendió las llamadas de atención por lo que noviembre de 1920 los regidores toman el siguiente acuerdo:[40]

"siendo uno de los principales deberes de la Municipalidad velar por la cultura y moralidad de los pueblos y en que no se guarda la compostura por niños y adultos que asisten a las exhibiciones cinematográficas los domingos en la casa de la Escuela Pública se acuerda suspender tales funciones."

Los espectáculos eran controlados para mantener la moral pública. Así, todo programa debe de ser sometido al gobernador de la provincia veinticuatro horas antes de su publicación, el cual, con anticipación, se somete a la aprobación del respectivo censor. Además, la persona que toman parte en un espectáculo público "deben de guardar perfecta decencia y compostura en sus trajes, gentes y palabras" (artículo \#28). También se estipula que en cada función debe de haber una autoridad encargada de velar por el orden público.[41] En un principio dichas autoridades eran nombradas y pagadas por el Estado, sin embargo mediante un acuerdo ejecutivo en 1911 se determinó que el empresario debía de sufragar todos los gastos.[42] El pago no se rige por tarifa única, sino que la normativa permite que el número de policías y el sueldo a pagar los determine la autoridad de policía de cada lugar.

Hasta 1920, es corriente que los niños solos o acompañados por adultos concurran sin restricciones a las funciones de teatro y a los cines. El clamor de lograr una mayor moralidad en la sociedad llega al Congreso donde se dan explicaciones sobre los daños que causan en los niños el hecho de que observen espectáculos nocivos para su edad y "que la asistencia de los niños a esas diversiones los acostumbra al ocio, a la vida muelle, al lujo, y los aleja, por displicencia o cansancio del trabajo, de las disciplinas austeras que forman al hombre 
correcto".[43] Esta preocupación refleja el impacto de la cultura de masas en el proyecto civilizador de los liberales.

Por ello en ese año se da un decreto ejecutivo, donde se prohibe a los niños de ambos sexos, menores de 14 años, entrar a los teatros o cinematógrafos en las noches, aún cuando vayan acompañados de personas mayores de edad. Se les permite asistir de día, pero a la vez se les prohibe a los teatros y cines exhibir funciones no aptas para niños durante el día. El cumplimiento de dichas disposiciones queda a cargo del Censor de Teatros, quien vela porque la programación de los establecimientos mantenga estas regulaciones. La sanción para el que no cumpla lo estipulado contempla incluso el cierre del local.[44] Un año más tarde se emite otro decreto ejecutivo más estricto, pues se revisa la edad de los niños y se eleva a 15 años.[45]

El control se dirige también a la temática. Así, se prohibe en los teatros y cines la representación de obras o la proyección de películas que traten, entre otros, temas policíacos, irrespeten los cultos religiosos o que "menoscaben la moral y las buenas costumbres". En este decreto se imponen multas en dinero a los que no cumplen con las disposiciones, y si reinciden se le ordena a la policía que cierre el establecimiento por seis meses.[46] Debido a lo difícil de construir locales adecuados y a la necesidad de las escuelas de colectar fondos en las comunidades, en las mismas se realizan representaciones teatrales y se proyecta cine, pero estas se encuentran bajo la tutela y las disposiciones de la Secretaría de Instrucción Pública. Por su parte la Iglesia a fines de la década de 1920 lanza una fuerte campaña contra el cine y trata de prevenir a los feligreses de sus peligros al decir que:

"el cine es el mar donde ha naufragado la inocencia de millones de niños y jóvenes. El cine es el sitio de la ciudad o pueblo donde se cometen más pecados. El cine, por fin, es la antesala del infierno. ¡Padres y madres, mirad a lo que exponéis a vuestros hijos al permitirles ir al cine si es inmoral".[47][48]

\section{CONCLUSIÓN:}


En conclusión, se puede observar que a fines del siglo XIX y principios del XX en la mayoría de las localidades ubicadas en el Valle Central, se da el proceso por medio del cual se entroniza la cultura de masas. Esta se inicia con el fútbol y continúa con el cine. Por lo tanto, se da una diversificación de las diversiones públicas, pues la cultura de masas modifica el marco de las mismas y a la vez abre espacios para insertarse en la cultura popular. De ahí el advenimiento de bailes en los salones, o la proyección de cine, en la plaza, en la escuela, y finalmente en un centro específico para ello. A la vez hay una revalorización de lo popular pues el fútbol se incorpora a la vida de la plaza y a la fiesta religiosa.

Frente a dicho proceso se observa que la diversificación de la diversión pública estimula una mayor presencia del Estado en la regulación de la vida cotidiana de los habitantes. Por ello se observa en este período un mayor número de leyes, reglamentos y disposiciones que tienden a normar la vida de la población en una serie de campos. Sin embargo, esta respuesta de las autoridades para ejercer el control social de los pueblos es diversificada, ya que mientras la Iglesia apela a una sanción moral, a través de la prédica de los sacerdotes, las pastorales de los obispos o por medio de la prensa católica, el Estado procede a reglamentar las nuevas y viejas actividades de la diversión pública.

[1] Colección Leyes y Decretos(C.L.D.) Decreto XXXV, 30 de octubre de 1849.

[2] Véase Leyes usuales de Costa Rica. Imprenta Nacional. 1905 y 1994. También: Patricia Fumero. Teatro, público y Estado en San José. Editorial Universidad de Costa Rica. 1996.

[3] Colección Leyes y Decretos (C. L. D.) Reglamento de Orden y Policía de la Ciudad de San José, 1908, art. 170.

[4] Ibid. Art. 174.

[5] El Mensajero del Clero, enero de 1920. N. 78, p. 584.

[6] Ibid. P.585.

[7] Ibid. P. 5869.

[8] A.C.M. Consulta 1893. Caja 40. 
[9] A.N.C.R. Congreso. 4387, fol. 1.

[10] A.N.C.R. Congreso, 4387, fol. 4.

[11] Ibid, fol. 5.

[12] Ibid, fol. 7.

[13] A.N.C.R. Congreso, 11263.

[14] A.N.C.R. Congreso, 1150.

[15] A.M.M.. Tomo 3, octubre de 1920.

[16] C.L.D.. Acuerdo 73 del 17 de diciembre de 1930.

[17] Revista Costarricense 119, 17 de setiembre de 1993, p. 361.

[18] A.C.M. Hojita Parroquial, febrero de 1927, p.30.

[19] Ob. Cit., mayo de 1972, p.91.

[20] Ibid.

[21] Ob., Cit., oct., 1927, p. 176.

[22] C.L.D. Código Fiscal, Ley del 27 de diciembre de 1907, art. 11.

[23] Op. Cit. Art.15, inciso b.

[24] Op. Cit. Art. 27, inciso 2.

[25] Marco Huertas. Entrevista realizada el 20 de agosto de 1996.

[26] C.L.D. Ley de Licores de 1907. Art. 32.

[27] Op. Cit. Art. 35.

[28] Op. Cit. Art. 30.

[29] C. L. D. Ley de Licores de 1907.

[30] A. N. C. R. Gobernación circular 1609, 16 de noviembre de 1910.

[31] A. N. C. R. Policía. Circular 479, 28 de diciembre de 1910. 
[32] C. L. D. Ley de cierre dominical del 8 de junio de 1915 y ley del 24 de noviembre de 1924.

[33] ACM. Stork, Gaspar. Carta Pastoral. 19 de marzo de 1912 p.8. Ver: Chester Urbina. El futbol en San José.Tesis de Licenciatura en Historia.1996. p.143

[34] Eco Católico, 7 de julio de 1900., n. 23, p.179.

[35] ANCR. Gobernación, n. 841.

[36] Leyes usuales de Costa Rica. Reglamento de Teatros y Espectáculos Públicos. Op. Cit.

[37] Op. Cit. art. 30.

[38] AMM. Actas Municipales. T.5. 1926.

[39] AMM. Actas Municipales. T.3. 1920.

[40] AMM. Actas Municipales. T.3. 1920.

[41] Reglamento de Espectáculos. Art. 38 y Reglamento de Policía art. 165.

[42] C.L.D. Acuerdo Ejecutivo N. 965, 19 de diciembre de 1911.

[43] C.L.D. Policía. N. 108. 1 de julio de 1920.

[44] Ibid.

[45] C.L.D. Decreto Ejecutivo, N.7 del 11 de noviembre de 1921.

[46] Ver: Gilberth Acuña y otros. El origen del cine en Costa rica. Memoria. Seminario de Graduación. Licenciatura en Historia, U.C.R., 1996. También:en: Juan José Marín. "Melodías de pereversión y subversión. Una aproximación a la música popular en Costa Rica. Ponencia III Congreso Centroamericano de Historia.1996

[47]ACM. Hojita Parroquial. Dic. 1927, p. 184.

Siglas: A.C.M.= Archivo Curia Metropolitana.

A.N.C.R. $=$ Archivo Nacional de Costa Rica. 
A.M.M.= Archivo Municipal de Moravia.

C.L.D. $=$ Colección de Leyes y Derecho. 